\title{
Travel Grants to CPSA/SQSP Joint Conference
}

CPSA/SQSP Joint conference, Quebec, City July 29-August 1, 2000

The Canadian Political Science Association receives a travel grant from the Social Sciences and Humanities Research Council of Canada to assist members to come to the annual meeting from distant places. These funds are intended in particular to facilitate participation by junior members. Funds will be apportioned by February 29, 2000. Travel grants will be allocated on a proportionate basis to applicants who meet all five of the following criteria:

(1) Applicants must be members of the Canadian Political Science Association for two consecutive years prior to application.

(2) Applicants must be paper-givers at the conference (one grant per paper).

(3) Applicants must: (a) be non-tenured faculty members, or (b) be students in the third or subsequent year of a doctoral programme, or (c) have received their doctorate in the past five years and not be currently employed full time.

(4) Travel grants will be awarded to applicants who did not receive a travel subsidy the previous year.

(5) Travel grants will be awarded only to applicants who are employed (in the case of 3[a]), study or reside (in the case of 3[b]) or reside (in the case of $3[\mathrm{c}]$ ) more than $500 \mathrm{~km}$ from the conference site.

To be considered, requests for travel funds must reach the Secretary-Treasurer, Canadian Political Science Association, Suite 204, 260 Dalhousie Street, Ottawa, Ontario K1N 7E4, by February 15, 2000. Application forms are available from the Association (telephone: 613-562-1202; fax: 613-241-0019; e-mail: cpsa@csse.ca). 